\title{
¿Por qué enseñar el Tamazigh en España?
}

\author{
RACHID RAHA AHMED \\ Investigador en Antropologia Amazigh (Bereber) \\ Presidente de la Asociación de Cultura Tamazight en España.
}

No es de extrañar que muchos españoles desconozcan el significado del término tamazight. Se podría pensar que su conocimiento está restringido a la esfera académica e intelectual. Pero tampoco en este caso, porque ni siquiera figura en el diccionario de la Real Academia, y eso que conlleva un triple significado, a saber: mujer, cultura y lengua de los pueblos amazighs. Significados estrechamente ligados entre sí, porque la cultura es vehiculada a través de la lengua, la cual es trasmitida -desde la prehistoria, hace unos 10.000 años- de generación en generación por la mujer tamazight, verdadera guardiana de esta milenaria cultura mediterránea.

En la actualidad atraviesa un momento crucial de transición de su fase natural a la artificialidad, de la oralidad a la escritura, con el fin de asegurar su supervivencia y su desarrollo, siempre que las autoridades políticas, tanto de Tamazgha, -o sea Norte de Africa-, como de Europa occidental deciden su necesa- 
ria enseñanza. Lo que ha llevado a que cuatro asociaciones, domiciliadas en cuatro países del Mediterráneo occidental (España, Francia, Marruecos y Argelia), dirigieran una carta al Presidente del Gobierno español, el pasado noviembre, solicitando la puesta en práctica de la enseñanza del tamazight. La respuesta del Ejecutivo, el pasado marzo, como cabía esperar, no fue nada satisfactoria, aunque pueda reflejar buenas intenciones.

¿QUE ES EL TAMAZIGHT?

Pero, ¿qué es el tamazight?. Su desconocimiento resulta ser una inexplicable paradoja, cuando es evidente que esta cultura está estrecha e íntimamente ligada a la historia de España. De hecho no es normal que durante la celebración del Quinto Centenario del Descubrimiento de América en 1992, se haya hecho completamente caso omiso del tamazight, negando injusta y deliberadamente la existencia de un legado amazigh, que continúa siendo ocultado, y resulta una ofensa a los Amazighs, en el Legado Andalusí 95/96. Porque los arabistas españoles siguen hasta ahora cometiendo el grave error de confundir el tamazight con lo árabe. Como dice un amigo, no hay mayor calamidad para un pueblo que ser confundido con pueblos circundantes, algo aún peor que ser desconocido. No lo entendí́ así el recordado investigador Jacinto Bosch Vilá, quien no se equivocaba al afirmar que la historia musulmana de España es en gran parte una historia de los imazighen. ¿Acaso las tropas de Tariq que conquistaron la península ibérica en el 711 , muchos reinos de taifas, las dinastías almorávides, almohades y amariníes, así como los numerosos asentamientos musulmanes de Levante, Cataluña, Islas Baleares, Norte de Andalucía y Extremadura ¿no eran imazighen?.

Pero, ¿cómo puede ser que después de casi más de siete siglos de permanencia en Al-Andalus, el tamazight no haya dejado hue- 
llas lingüísticas en la lengua castellana, como es el caso del árabe? La toponimia amazigh es escasa, pero las excavaciones arqueológicas del equipo de Miguel Barceló nos incitan a otra versión de la interpretación: lo árabe dominaba en las ciudades, materializado por una élite intelectual y administrativa, como lengua de ciencia y de las letras por excelencia, a cuyo prestigio han colaborado no solamente los árabes, sino también judíos, persas, hispanos convertidos y por supuesto los imazighen. En cuanto al tamazight, dominaba en la periferia y los campos como lengua exclusivamente oral, sin archivos escritos. Lo mismo ha pasado en Islas Canarias, donde el guanche, derivado del tamazight, desapareció completamente sin dejar documentos, pero sí restos arqueológicos con las piedras con inscripciones tifinagh, o sea líbico-beréber.

La debilidad de esta lengua reside, eso sí, en su característica inherente de ser transmitida oralmente, lo que, sin embargo, no impidió su resistencia contra viento y marea a todas las invasiones lingüísticas del pasado norteafricano, (fenicia, romana, bizantina, árabe y europea), pero que en la actualidad se está borrando del mapa de muchas regiones amenazada de extinción. Ejemplo de ello, es su retroceso en Mali y Níger a causa de las limpiezas étnicas desencadenadas por los gobiernos de estos estados contra los tuaregs.

Pero su regresión se debe fundamentalmente al fenómeno de arabización que azota las zonas periféricas y montañosas del Norte de África, su principal refugio antes de la llegada del colonialismo europeo, el cual obró por la desestructuración de las bases socio-políticas de las comunidades amazighs. El retroceso de tamazigh se reforz6 aún más con el acceso a la independencia de los países del Magreb, negando hasta ahora su reconocimiento institucional y oficial, relegándola siempre a una posición marginal, aunque últimamente los gobiernos de estos países han augurado señas de buenas intenciones encaminadas a su enseñanza. 
Pero si el tamazight es una lengua originaria del Norte de África, ¿por qué enseñarla en España?.

El idioma es el instrumento más adecuado y directo para acceder al conocimiento de otras culturas, primera regla que podría adelantar cualquier antropólogo. Así pues, conocer el tamazight es permitirse adentrarse directamente en el conocimiento de la idiosincrasia, creencias religiosas y manifestaciones culturales de unos pueblos, que antaño formaban parte integrante de la península Ibérica, eternos vecinos de España y Europa, y que ascienden hoy a más de 20 millones de personas; en el conocimiento de la civilización de unas comunidades inmigrantes asentadas sobre todo en Cataluña, Madrid y Andalucía, con más de 50.000 personas originarias del Rif, y de la comunidad autóctona de Melilla, que forma un $40 \%$ de su población. Esta ciudad ha sido últimamente protagonista de un fuerte y vivo debate sobre la cuestión de incluir el tamazight como lengua cooficial en su Estatuto de Autonomía, el cual fue aprobado sin mencionarla explícitamente.

La multiculturalidad, hacia la cual necesariamente nos estamos encaminando, puede ser una realidad solamente si se basa en multilingüismo como medio de prevenir actitudes de racismo y xenofobia, sobre todo respecto al mundo de la inmigración, que suscita problemas de integración, fundamentalmente en la segunda o tercera generación. Los psicólogos y los pedagogos, casi unánímemente, afirman que para combatir los altos índices del fracaso escolar de los niños inmigrantes, es necesario integrar en el sistema educativo sus afinidades culturales, sociales y familiares, es decir, que la enseñanza de la lengua materna es un necesidad imprescindible para la escolarización, que les puede permitir adquirir habilidades de lectura, escritura y demás saberes, en concordancia con lo manifestado reiteradamente por la convención de la UNESCO. 
En esta sintonía, fue acordado por la Ministra de Asuntos Sociales, y aprobado por el Consejo de Ministros en el Plan de Integración Social de los inmigrantes el pasado diciembre, lo siguiente: "La integración debe basarse necesariamente en acciones de reconocimiento y respeto a sus tradiciones y a sus manifestaciones culturales y que la educación en castellano debería ser coordinada con la lengua y cultura maternas". Algo que está, en cierta manera, en contradicción con el programa -de carácter experimental- acordado entre los Gobiernos de España y Marruecos, de introducir la enseñanza del árabe clásico a los alumnos de origen marroquí, como los que se han llevado a cabo -y se llevan aún- en Francia, Bélgica, Holanda, Alemania. Los programas aplicados en estos países, salvo Holanda, -y que cuentan con mayores comunidades ascendiendo a casi 2 millones de Amazighs- no han logrado sus principales objetivos, porque el problema sigue siendo el mismo, como pasa en los propios países del Magreb; se sigue ignorando la enseñanza de las lenguas maternas (árabe dialectal y dialectos amazighs) en contra de lo que aconseja y enuncia la UNESCO en la aplicación del principio educacional.

Los niños magrebíes siguen encontrando problemas en la adquisición de la lengua árabe clásica, fundamental para acceder al conocimiento de la civilización araboislámica y a las enseñanzas religiosas del Corán, porque no se coordinan con el árabe dialectal ni con el tamazight. Igual ocurre con el plan de alfabetización de los adultos, de gran importancia especialmente para las mujeres, ya que éstas son las verdaderas artífices de una necesaria planificación familiar.

En definitiva, estos programas llevados a cabo en la Europa occidental se hubiera podido traducir con más efectividad y eficacia si hubieran ido acompañadas de la enseñanza de las lenguas europeas y árabes con los idiomas maternos. Por ello en la autonomía de Melilla la enseñanza del tamazight se impone como 
el mejor medio de integrar en el sistema educativo a los niños de la comunidad amazigho-musulmana.

En conclusión, la enseñanza de las lenguas acorta distancias entre culturas y comunidades. El estado español tiene mucho que ganar apostando por enseñar el tamazight. Así podrá reconciliarse, en cierto modo, con su pasado hacia los amazighs por una parte, y por otra parte aspirar a una mayor integración multicultural de las comunidades inmigrantes y la población autóctona de Melilla. Además, podría permitir estrechar lazos de amistad y cooperación con los pueblos norteafricanos. 